\title{
A Review on Alternative Gold Recovery Reagents to Cyanide
}

\author{
Mertol Gökelma, Alexander Birich, Srecko Stopic, Bernd Friedrich \\ IME Process Metallurgy and Metal Recycling, RWTH Aachen University, Aachen, Germany \\ Email: mgoekelma@ime-aachen.de
}

Received 26 May 2016; accepted 15 August 2016; published 18 August 2016

Copyright (C) 2016 by authors and Scientific Research Publishing Inc.

This work is licensed under the Creative Commons Attribution International License (CC BY). http://creativecommons.org/licenses/by/4.0/

(c) (7) Open Access

\begin{abstract}
The importance of gold recovery from low grade ores and flotation tailings is continuously increasing due to raising gold demand and thereby high gold prices. However, due to raising social awareness of the ecological impacts of cyanidic gold extraction and environ-mental specifications, the development and the implementation of alternative hydrometallurgical extraction processes have been a focus for many research institutions in last decades. Present work gives a comparison between compatible extraction reagents, with focus on less harmful processes. The target of this review is to point out the best cyanide-free processes of following methods and reagents: Bioleaching, Chlorination, Aqua Regia, Bromine, Thiocyanate, Thiosulfate and Thiourea leaching. For this propose, the gold leaching reagents are described and discussed in terms of their environmental and economical points of view. As result of this comparison, thiourea stands out as the most promising alternative gold leaching reagent to cyanide.
\end{abstract}

\section{Keywords}

Hydrometallurgy, Leaching, Cyanide, Alternative Reagents, Recovery

\section{Introduction}

Gold is a rare element with a concentration of just $0.005 \mathrm{ppm}$ in earth crust. This low concentration is a big challenge for gold processing due to a need of upgrading by factor of 3000 to 4000 to receive commercial concentrations. Due to its siderophile properties, gold is frequently bonded with silver, copper and other metals and it also occurs in sulfidic ores such as pyrite, tetrahedrite, chalcopyrite and arsenopyrite [1].

Gold has excellent chemical resistance and electrical conductivity. These featured properties of gold make it a useful material for the electronical industry, where it is used as coating for electrical contacts. Gold has also high importance as save funds, due to its high price which results from the rareness and chemical resistance. Besides that, it is used in jewelry, coinage, ornaments, gilding, etc.

How to cite this paper: Gökelma, M., Birich, A., Stopic, S. and Friedrich, B. (2016) A Review on Alternative Gold Recovery Reagents to Cyanide. Journal of Materials Science and Chemical Engineering, 4, 8-17. 
Today's gold ore reserves are assessed around 51,000 tons; it means the reserves are almost 20 times the world annual primary production. Gold production numbers and the gold price are shown in Figure 1 [1], [2].

In last four decades, gold production has doubled in the world and new hydrometallurgical processes have been developed connectively. The increase in gold production and price point out that the recovery of gold from secondary materials will gain more importance in next year.

Outstanding chemical resistance of gold becomes a disadvantage in hydrometallurgical processes and it is not easy to find reagents which can easily dissolve gold. The reagents which can dissolve the gold, like cyanide, chloride or sulfur complexes, are mostly aggressive and very toxic [2] [3]. Therefore, we face environmental problems during chemical processing. New leaching reagents and new leaching techniques have been searched in order to overcome environmental problems caused by cyanidation. Moreover, dissolved gold in less toxic or nontoxic solutions are also more suitable for further lab-scale researches [1], [4].

The environmental impact is not the only problem which raises the demand for new extraction technologies. There are other disadvantages of cyanide leaching, such as big losses in processing of preg-robbing ores. All gold concentration and refining processes generate residues with a remaining gold content. Those residues arise mainly in tailings from different extraction processes like cyanidation, flotation, amalgamation, etc. conventional flotation, electrolysis and leaching processes. Due to low gold content and huge amount of those residues, recycling faces with economic and environmental problems [1].

A general overview of gold processing steps is shown in Figure 2. Gold contents are roughly estimated because of very inhomogeneous feeding material, and varying type and efficiency of the used processes.

The feeding material is firstly prepared by mechanical processes as grinding, crushing, and sieving. Subsequently, gold minerals with a gold content less than $1 \%$ are concentrated via gravity concentration and flotation. A pre-concentration of gold is quite important to enable an effective and economical processing with further chemical treatment methods as leaching, precipitation and refining [5].

Gravity concentration process separates the part of ore body that contains gold with higher specific gravity than the host rocks. The effectiveness of gravity concentration arise from the high difference in the specific density between gold, with a density of $19.3 \mathrm{~g} / \mathrm{cm}^{3}$, and typical ore which has a density of about $2.6 \mathrm{~g} / \mathrm{cm}^{3}$.All gravity concentration devices create a gravitational movement between the gold and host rock particles. It concentrates the heavy gold particles at the bottom of the pan while the light gangue is washed off on top. The most known gravity methods which are collecting gold bearing heavy particles without dissolving the mare sluice boxes, jigs, shaking tables, spirals and rotating cones [1], [6], [7].

Flotation is also a widely used concentration technique which utilizes different surface properties of particles and their wetting behavior. The minerals with hydrophobic surfaces attach to air bubbles passing through a suspension and float to the surface creating a froth. This process is potential to be used for recovery of fine gold as well as other tailings from gravity concentration and leaching. Desliming is generally applied to remove very fine particles. Froth flotation is effective in the processing of the material in the size range $850 \mu \mathrm{m}$ to $100 \mu \mathrm{m}$ [8].

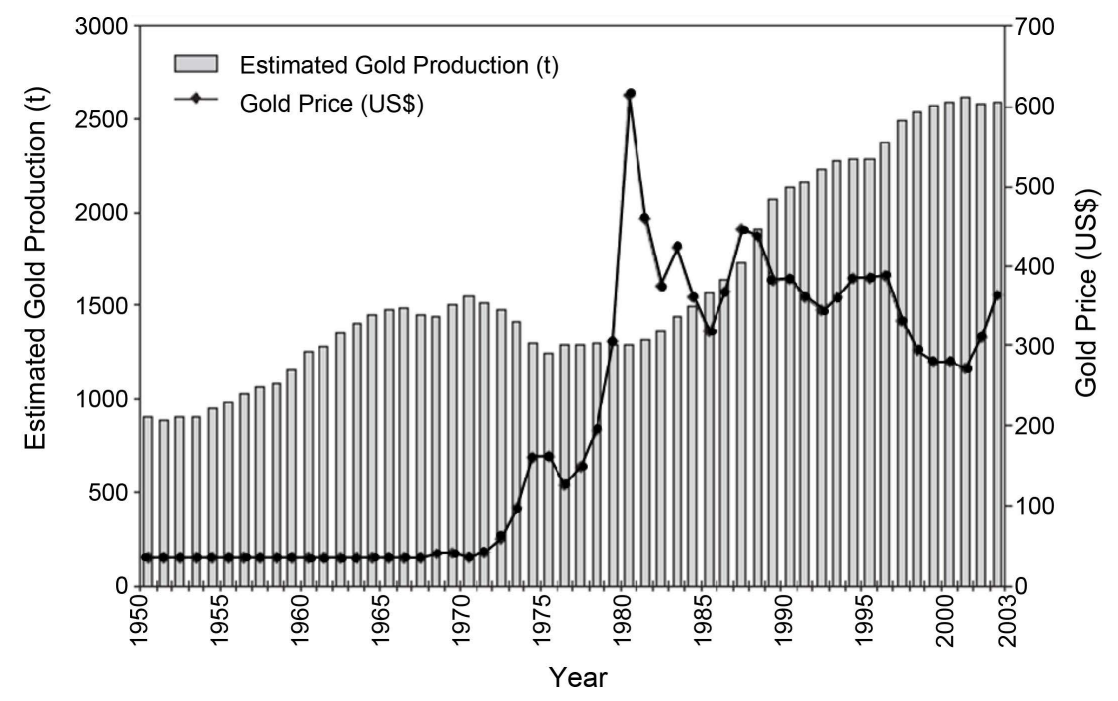

Figure 1. Gold production amount (t) and corresponding gold price (\$) [1]. 


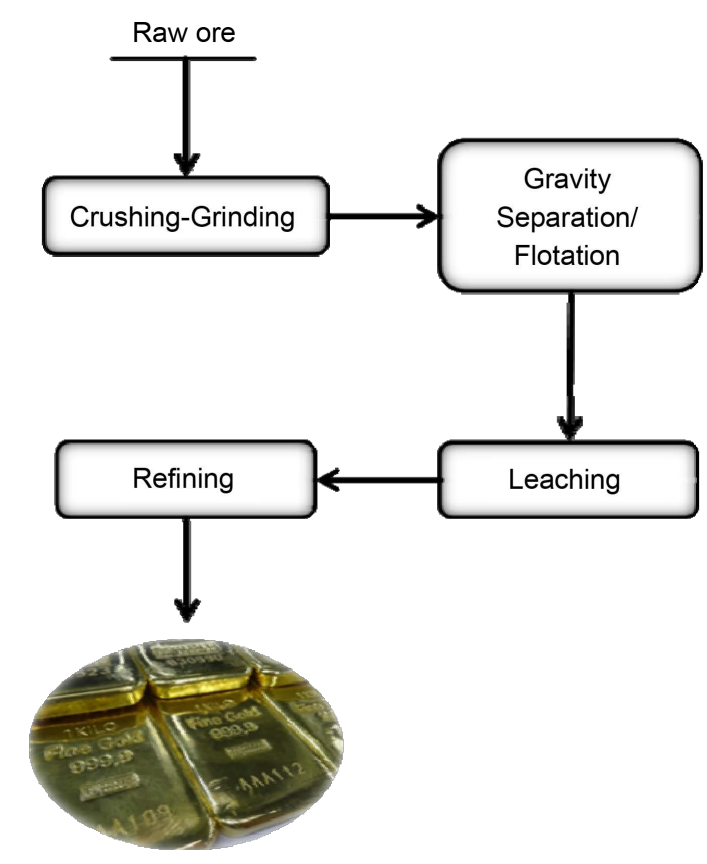

Figure 2. A general overview of gold processing steps.

Flotation tailings are obtained as by-product and huge amounts of flotation tailings are present in the world. Especially old flotation tailings contain more gold content due to overage and inefficient processing methods. The amount of gold in tailings depends on the feed. Flotation tailings from ores contain from 1.5 to $3.5 \mathrm{ppm}$ as reported in some works. This constitutes a potential resource for further treatment [9]-[13].

After gold content is increased by physical and mechanical methods the concentrate is used as feeding material for next steps. Gold concentrates are processed by chemical methods in order to recover up to > 99\% gold, depending on type and efficiency of the processes [14]. The widely used chemical treatment process is the leaching with cyanide. After leaching, the pregnant solution is treated to precipitate the gold content via cementation or, more effectively, in resin pulps [1], [5]. However, because of high toxicity of cyanide it has been discussed in last decades the possibilities of replacing cyanide with other reagents. Therefore, the environmental impact of cyanide is shortly introduced in the next chapter.

In order to produce gold with a purity of $99.99 \%$ or higher, a refining electrolysis is necessary to separate especially noble metal impurities [15].

Present work aims to present a review on the recovery of gold by hydrometallurgical processes. Different reagents are comparatively investigated in order to indicate their advantages and disadvantages in terms of hazardousness and effectiveness in gold recovery. After giving a short overview of the state of the art, description and comparison of gold leaching reagents will follow to determine an alternative reagent to cyanide.

\section{Environmental Effects of Cyanide}

Cyanide compounds occur naturally as part of sugars or other compounds in certain plant-derived foods, including almonds, millet sprouts, lima beans, soy, spinach, bamboo shoots, sorghum and cassava roots. However, the total concentration of cyanide in these compounds is very low and a negative effect on animals hasn't been documented so far [6], [16].

The impact of cyanide to plants and living beings can be very different and strongly depends on the absorbed amount. For humans and animals cyanide is very toxic however, lower amounts can be transformed into less harmful components such as thiocyanate where at higher amounts cause irreversible damage. By oral intake cyanide in contact to gastric juice is converted to hydrogen cyanide which inhibits the intracellular respiration and causes intermediate cell death. The lethal dosage is $1.5 \mathrm{mg} \mathrm{CN}^{-}$per kg body weight [17].

The cyanide itself can get into the environment on two different ways: by evaporation from open leaching basins or by leakage. By cyanide leaching besides gold also other heavy metals like arsenic, nickel, cadmium, co- 
balt, copper and mercury can be extracted from gold resources and these dissolved metals have crucial impacts on environment as well [18].

In areas near gold leaching industry cyanide can pass soil and even contaminate the underground water. The cyanide concentration in these areas is too high for microorganism transformation to less harmful complexes whereby long term environmental problems arise [3].

However, it must be also noted that a huge amount of cyanide is used in other processes such as production of organic chemicals. Cyanide used in gold extraction presents the $20 \%$ of the while cyanide consumption in the world. It is also important to motivate other application areas to reduce the consumption or replace with other reagents [19].

\section{Alternative Gold Recovery Reagents to Cyanide}

The most important gold dissolution capable reagents are investigated in order to have a better overview from the point of economic and ecologic view. To facilitate the reagent comparison, cyanide is also briefly described.

Any compound that contains the cyanide ion $\left(\mathrm{CN}^{-}\right)$, consisting of a carbon atom triple bonded to a nitrogen atom is called cyanide. The simple cyanide salts are KCN and NaCN which are soluble in water and moderately soluble in ethanol. Cyanide leaching is the dominating technique to recover gold from primary and secondary resources for longer than 100 years. The dominance of this reagent results from a cost efficient and technical effective process with high yield and adequate dissolution rates. Cyanide dissolves gold by forming a soluble complex (Equation (1)) [3]-[5].

$$
4 \mathrm{Au}+8 \mathrm{CN}^{-}+\mathrm{O}_{2}+2 \mathrm{H}_{2} \mathrm{O}=4 \mathrm{Au}(\mathrm{CN})_{2}^{-}+4 \mathrm{OH}^{-}
$$

Numerous investigations on cyanide leaching have been undertaken to determine optimal process conditions. Best extraction results can be obtained in a basic solution at a $\mathrm{pH}$ level of about 10 , a temperature of $85^{\circ} \mathrm{C}$ and guaranteed oxygen supply.

A series of environmental accidents around the world raised concerns about this reagent in society. Another big disadvantage of cyanide is the low leaching efficiency of refractory sulfide minerals or gold resources that contain copper or carbonaceous preg-robbing materials. Additionally, these resources afford a higher demand of cyanide and decrease the dissolution yield. Generally an average gold extraction yield of $50 \%-80 \%$ can be obtained by heap or $99 \%$ by conventional leaching [1], [4].

The alternative reagents to Cyanide are described in the following:

\subsection{Aqua Regia}

Aqua Regia is a mixture of concentrated nitric and hydrochloric acid. This reagent belongs to the strongest chemical dissolver and is known as royal water because of its ability to dissolve gold. Neither any of the two acids alone are able to dissolve gold, but a mixture of about $1 / 4$ nitric acid and 3/4 hydrochloric acid is able to dissolve. The powerful oxidize nitric acid dissolves an infinitesimal amount of gold, forming trivalent gold ions. The dissolved gold ions react with chloride ions provided by hydrochloric acid to form tetrachloroaurate anions [1], [20].

The dissolving reaction is shown in following equation:

$$
\mathrm{Au}+\mathrm{HNO}_{3}+4 \mathrm{HCl}=\mathrm{AuCl}_{4}^{-}+\mathrm{H}^{+}+\mathrm{NO}+2 \mathrm{H}_{2} \mathrm{O}
$$

Aqua Regia reached extraction rates up to $100 \%$ in a few hours, depending on process parameters. It is also able to dissolve other noble metals like platinum, ruthenium and rhodium and is therefore also used to attack high gold alloys [21]-[23]. Aqua Regia is efficient alternative reagent to cyanide because of its extremely corrosive characteristic and chemical instability. Therefore it is just used in small and medium scale processes such as electrolyte in gold refining. Another disadvantage is the loss of containing silver by formation of $\mathrm{AgCl}$ [21], [22], [24].

\subsection{Chlorination}

Chlorine dissolves gold in aqueous solutions by formation of soluble $\mathrm{Ag}(\mathrm{I})$ and the more stable $\mathrm{Ag}(\mathrm{III})$ chloride complexes. The dissolution of gold occurs in two stages as shown in Equation (3) and Equation (4): Au(I) chlo- 
ride forms during the first stage on gold surface and then $\mathrm{AuCl}_{2}^{-}$forms during the second stage. These chlorides diffuse into the solution as $\mathrm{AuCl}_{2}^{-}$or oxidize further to $\mathrm{AuCl}_{4}^{-}$which is more stable, depending on the oxidizing potential of the solution [4], [21], [25]-[27].

$$
\begin{gathered}
\mathrm{Au}+\mathrm{Cl}^{-}=\mathrm{AuCl}+\mathrm{e}^{-} \\
\mathrm{AuCl}_{2}^{-}+2 \mathrm{Cl}^{-}=\mathrm{AuCl}_{4}^{-}+3 \mathrm{e}^{-}
\end{gathered}
$$

A big advantage of chlorination is the high dissolution rate compared to alkaline cyanide leaching which is due to higher solubility of chlorides in water. The processing of silver and lead containing minerals with chlorine is problematic because of the formation of insoluble chloride layers onto the gold surface. This causes a loss in metal recovery. Another disadvantage is the difficult handling of the strongly corrosive chlorine solution and the need for a closed reaction container because of formed chlorine gas [1], [28].

$\mathrm{PH}$ values lower than 1.5 and temperature between $50^{\circ} \mathrm{C}-70^{\circ} \mathrm{C}$ offers a yield of $99 \%$ in small-medium scales. The process needs very acidic conditions. Therefore, it is generally combined with different acidic reagents. The chlorination is capable for higher scale processing and has already been applied in industrially significant scale [4], [29]-[31].

\subsection{Bromine and Iodine}

Two other important halide leaching reagents with a similar dissolution reaction to chlorine are bromine and iodine. These reagents are strongly oxidizing and show much higher dissolution rates than cyanide leaching. The dissolution reaction can be summarized in following equations: [4], [32]-[35].

$$
\begin{aligned}
\mathrm{Au}+4 \mathrm{Br}^{-} & =\mathrm{AuBr}_{4}^{-}+3 \mathrm{e}^{-} \\
\mathrm{Au}+4 \mathrm{I}^{-} & =\mathrm{AuI}_{4}^{-}+3 \mathrm{e}^{-}
\end{aligned}
$$

Because of their difficult handling, high reagent costs and health issues, bromine and iodine haven't been used industrially [4], [36], [37].

\subsection{Thiocyanate}

The thiocyanate ion $\mathrm{SCN}^{-}$is an alternative less harmful leaching reagent to cyanide ( $\mathrm{NaCN}$ or $\mathrm{KaCN}$ ). Gold in an aqueous thiocyanate solution forms stable $\mathrm{Au}(\mathrm{I})$ and $\mathrm{Au}(\mathrm{III})$ complexes, as following reactions show: [4], [21], [22], [36]-[39]

$$
\begin{aligned}
& \mathrm{Au}+2 \mathrm{SCN}=\mathrm{Au}(\mathrm{SCN})_{2}+\mathrm{e}^{-} \\
& \mathrm{Au}+4 \mathrm{SCN}=\mathrm{Au}(\mathrm{SCN})_{4}^{-}+3 \mathrm{e}^{-}
\end{aligned}
$$

Best leaching conditions with thiocyanate can be obtained in the presence of a suitable oxidizing agent like iron, a $\mathrm{pH}$ level of the solution of about two and raised temperature. Iron catalyzes the gold extraction by raising the dissolution kinetics and increasing the stability of the thiocyanate ion. Iron(III) is reduced to iron(II) while oxidizing thiocyanate to the intermediate $(\mathrm{SCN})_{3}^{-}$and $(\mathrm{SCN})_{2}$ species, which are capable to oxidize gold. By increase of temperature the consumption of thiocyanate raises due to its increased oxidation. At optimal conditions a gold extraction yield of $95 \%$ can be obtained with thiocyanate, while dissolution rates are similar to those of thiourea [4], [6], [36], [37], [39], [40].

\subsection{Thiosulfate}

Another alternative for cyanide is thiosulfate $\left(\mathrm{S}_{2} \mathrm{O}_{3}^{2-}\right)$, which causes fewer environmental impacts and is also capable to dissolve gold efficiently. The metal dissolution generally occurs in neutral medium in the presence of oxygen: [4], [5], [22], [38], [41]

$$
4 \mathrm{Au}+8 \mathrm{~S}_{2} \mathrm{O}_{3}^{2-}+\mathrm{O}_{2}+2 \mathrm{H}_{2} \mathrm{O}=4 \mathrm{Au}\left(\mathrm{S}_{2} \mathrm{O}_{3}\right)_{2}^{3-}+4 \mathrm{OH}^{-}
$$

The dissolution rate of gold with alkaline thiosulfate is relatively slow but can be increased with an increased reagent concentration and process temperature. Furthermore, the addition of the dissolution catalysts copper and 
ammonia has a big impact on dissolution rate. To receive an adequate leaching yield a high reagent consumption is necessary. Therefore, thiosulfate is less economical than cyanide, which is the biggest disadvantage of thiosulfate besides the lower extraction rates [4], [21], [25], [29], [38], [41]-[43].

\subsection{Thiourea Leaching}

The organic compound Thiourea $\left(\mathrm{CS}\left(\mathrm{NH}_{2}\right)_{2}\right)$ poses an effective gold dissolution reagent, in terms of extraction rate, yield and environmental matters. In acidic solutions it forms an anionic complex to dissolve gold, as following equation shows: [1], [4], [5], [22], [44]

$$
4 \mathrm{Au}+8 \mathrm{~S}_{2} \mathrm{O}_{3}^{2-}+\mathrm{O}_{2}+2 \mathrm{H}_{2} \mathrm{O}=4 \mathrm{Au}\left(\mathrm{S}_{2} \mathrm{O}_{3}\right)_{2}^{3-}+4 \mathrm{OH}^{-}
$$

A gold extraction rate of $99 \%$ can be achieved at optimal conditions which are a low pH level of $1-2$ as well as the presence of oxygen and iron as an oxidant. Other advantages to cyanide are a low sensitivity to base metals and sulfur containing calcines, as well as adequate recovery from preg-robbing ores. Furthermore, health issues are less critical [4], [21], [25], [45]-[49].

Well known disadvantage of this reagent is its high consumption during the process due to reagent loss through oxidation. This is a big problem because of the high cost of thiourea. However, Zhang et al. reported that a mixture of thiourea, thiocyanate and ferric sulfate reduce the thiourea consumption and herewith the process costs at similar comparable process effectiveness [49].

\subsection{Bioleaching}

Bioleaching itself is not a method for dissolution of gold however, it is used to improve the leaching conditions of sulfide mineral resources. Hereby the demand of extraction chemicals and their environmental threat can be reduced. The treatment of these resources by roasting or pressure oxidizing leaching is less effective in ecological and economical aspects [50].

There are naturally occurring bacteria that generate energy from sulfur and iron oxidation and thereby catalyze the decomposition of sulfide minerals. These bacteria can be used to liberate encapsulated gold grains. The catalytic effect of bacteria can be described as follows: Elemental sulfur is formed by oxidation reactions involving Fe(III) and sulfur mineral (Equation (9)) whereby a sulfur coating forms on particle surface. The coating hinders further oxidation of the mineral and thereby enclosed gold particles cannot be extracted by leaching anymore. The bacteria oxidize the sulfur coating and increase the porosity of sulfide particles. Furthermore, the bacteria oxidizes Fe(II) to Fe(III), which is again necessary for metal sulfide decomposition [22], [51], [52].

$$
\mathrm{FeS}_{2}+\mathrm{Fe}\left(\mathrm{SO}_{4}\right)_{3}=3 \mathrm{FeSO}_{4}+\mathrm{xS}
$$

The first and possibly most important benefit of bioleaching is the minimal damage it causes to the environment. Another advantage of Bioleaching is a quite simple process that does not require a lot of expertise to operate or complicated machinery. In comparison with the large capital investment of a smelting plant, simplicity of bioleaching process lead to cost benefits [22], [51].

The bacteria leaching process is effective and clean method but there are unfortunately some disadvantages like the slow reaction rate of $48-72$ hours and a difficult process control. One reason for the slow rate is that bacterial digestion of sulfide and sulfur ores is an exothermic reaction causing an increase in temperature. By exceeding the working temperature of mesophilic bacteria all reactions die down. That is why ores with high sulfide content are difficult to process. Besides this other factors as $\mathrm{pH}$, pulp density and oxygen concentration have a high influence to the process [51], [53]-[55].

The "bio" name addresses a more environment-friendly method of separating metals. However, there are some effects caused by bioleaching that may also have a negative impact on the environment. For instance sulfuric acid is created in the process. Extended use can cause the acidification of the water to $\mathrm{pH} 1$ which can be absorbed by the nearby groundwater [1], [22], [45], [51], [52].

Biohydrometallurgical processing of flotation tailings were presented in the work of M.G. Sagdieva et al. and over $90 \%$ efficiency was recorded [56].

\section{Conclusions}

The reagents for gold recovery processes are reviewed in the current paper based many valuable works of dif- 
ferent scientists. Following Table 1 grants an overview of the most important properties of the agents in terms of their applicability and toxicity.

The results and remarks of the current work can be summed up as following:

Aqua Regia is efficient reagent but not recommended due to its toxicity as well as deficiency for large scale applications and very corrosive characteristics which damage leaching tanks too fast.

Chlorination, thiocyanate and thiosulfate leaching might be alternatives to cyanide from the point of environmental view but generally the economic issues make hard to replace those processes with cyanidation due to their quite high reagent consumption and high temperature requirements. Moreover, chlorination and thiocyanate leaching processes are not adaptable for large scale applications.

Bioleaching shines as a promising pre-treatment agent to decrease the reagent consumption. Moreover, it has minor damage to the environment, process simplicity and affordable capital investments. Optimization of parameters such as concentration, feeding speed and sulphuric acid generation are needed. However, very long time in comparison with other processes is necessary and therefore, it can be only used as a promoter of different reagents used in gold recovery.

Bromine and especially iodine are very promising reagents in terms of ecological and technical points of view. They offer a high extraction yield at quite short time and causing minimal environmental impacts. The big disadvantage of these reagents is their high reagent consumption and cost issues accordingly. Therefore, application of these reagents in an affordable industrial process is not possible at the moment. However, an acceptable reagent recovery for bromine and iodine leaching is still under investigation to fulfill the requirements to be an economic process.

Thiourea is a strong alternative to cyanide with its very high gold dissolution rate and relatively high efficiency. Thiourea is also favorable because it doesn't need neutralization step which normally causes additional expenses during cyanidation process however cyanidation process requires lower reagent consumption to dissolve gold. However, according to recent works, thiourea, thiocyanate and ferric sulfate mixture decrease thiourea consumption. Thiourea leaching process has still big potential to be developed such as leaching parameters and recyclability of the reagent.

In spite of some promising results of some reagents such as, thiourea, iodine and chlorination it should be taken in to account that those applications are young methods and less developed than cyanide in terms of understanding of the process design and procedure. Therefore, more experimental researches are needed to make more reliable assessments.

Table 1. Comparison of different leaching reagents.

\begin{tabular}{cccc}
\hline Reagent & Toxicity & Advantages & Disadvantages \\
\hline Cyanide & Very high & High dissolution rate & Environmental issues \\
Agua Regia & High & High dissolution rate & No feasible large scale applications \\
Chlorination & Medium & Proven technology & No feasible large scale applications \\
Bromine \& Iodine & Low & Good efficiency & High temperatures required \\
Thiocyanate & Medium & Righ dissolution rate & High reagent costs \\
Thiosulfate & Medium & Cheap reagent & No feasible large scale applications \\
& & Proven technology & Limited availability \\
Thiourea & Medium & High dissolution rate and speed & High reagent consumption \\
& & Reduction of reagent consumption & Dissolution of heavy metals besides gold \\
Bacteria & Low & Higher leaching yield & Slow reaction \\
& & Difficult process control
\end{tabular}




\section{Future Prospective}

An alternative reagent to cyanide has been searched for a long time due to environmental issues. However, while doing an assessment about alternative reagents, the huge amount of secondary gold residues in the world must be taken into account. Therefore, for promising reagents, in this case thiourea, must be investigated in lab-, demo- and finally in industry-scale to prove its applicability for huge amounts.

\section{References}

[1] Marsden, J. and House, I. (2006) The Chemistry of Gold Extraction: SME.

[2] Mineral Commodity Summaries, “Gold Production in World” 2012_George_US Geological Survey.

[3] US Department of Health and Human Services, “Toxicological Profile for Cyanide,” 2006.

[4] Syed, S. (2012) Recovery of Gold from Secondary Sources-A Review. Hydrometallurgy, 115, 30-51. http://dx.doi.org/10.1016/j.hydromet.2011.12.012

[5] La Brooy, S.R., Linge, H.G. and Walker, G.S. (1994) Review of Gold Extraction from Ores. Minerals Engineering, 7, 1213-1241. http://dx.doi.org/10.1016/0892-6875(94)90114-7

[6] Gasparrini, C. (2012) Gold and Other Precious Metals: From Ore to Market. Springer Science \& Business Media, Berlin.

[7] Gül, A., Kangal, O., Sirkeci, A.A. and Önal, G. (2012) Beneficiation of the Gold Bearing Ore by Gravity and Flotation. International Journal of Minerals, Metallurgy, and Materials, 19, 106-110. http://dx.doi.org/10.1007/s12613-012-0523-4

[8] Mitchell, C.J., Evans, E.J. and Styles, M.T. (1997) A Review of Gold Particle-Size and Recovery Methods. British Geological Survey, Technical Report WC/97/14, Overseas Geology Series.

[9] Bicak, O., et al. (2012) Flotation of Yenipazar (Yozgat) Complex Sulphide Ore. Department of Mining Engineering, Hacettepe University, Ankara, 391-399.

[10] Daniel, A. and Downing, B.W. (2011) Investigating the Reprocessing of Carolin Mine Tailings. Proceedings Tailings and Mine Waste 2011, Vancouver.

[11] “New Carolin Gold Corp Press Release,” August 2012.

[12] Ziyadanogullari, R. and Tegin, I. (2008) The Effect of Sulfurization Process on Flotation of Copper Ore Containing Gold and Silver. Journal of Minerals and Materials Characterization and Engineering, 7, 193-202. http://dx.doi.org/10.4236/jmmce.2008.73015

[13] Barr, G., Grieve, W., Jones, D. and Mayhew, K. (2007) The New CESL Gold Process. ALTA 2007 Proceedings, Perth.

[14] Manning, T.J. and Kappes, D.W. (2016) Heap Leaching of Gold and Silver Ores. Gold Ore Processing, Elsevier, 413-428. http://dx.doi.org/10.1016/B978-0-444-63658-4.00025-6

[15] Dorin, R. and Woods, R. (1991) Determination of Leaching Rates of Precious Metals by Electrochemical Techniques. Journal of applied electrochemistry, 21, 419-424. http://dx.doi.org/10.1007/BF01024578

[16] Oelsner, D.-C.K., Dornig, D. and Uhlemann, R. (2001) Abbauverhalten von komplexen Cyanidverbindungen. Landesamtes für Umwelt und Geologie.

[17] Health Canada (1979) Cyanide [Technical Document-Chemical/Physical Parameters].

[18] BBU (2008) Goldbergbau-Verfahren zur Goldgewinnung und Auswirkungen auf die Umwelt.

[19] Logsdon, M.J., Hagelstein, K. and Mudder, T. (1999) The Management of Cyanide in Gold Extraction. International Council on Metals and the Environment, Ottawa, ON.

[20] Park, Y.J. and Fray, D.J. (2009) Recovery of High Purity Precious Metals from Printed Circuit Boards. Journal of Hazardous Materials, 164, 1152-1158. http://dx.doi.org/10.1016/j.jhazmat.2008.09.043

[21] Kuzugüdenli, O.E. and Kantar, Ç. (1999) Alternates to Gold Recovery by Cyanide Leaching. Erciyes Üniversitesi Fen Bilimleri Enstitüsü Dergisi, 15, 119-127.

[22] Sparrow, G.J. and Woodcock, J.T. (1995) Cyanide and Other Lixiviant Leaching Systems for Gold with Some Practical Applications. Mineral Processing and Extractive Metallurgy Review, 14, 193-247. http://dx.doi.org/10.1080/08827509508914125

[23] Sheng, P.P. and Etsell, T.H. (2007) Recovery of Gold from Computer Circuit Board Scrap Using Aqua Regia. Waste Management \& Research, 25, 380-383. http://dx.doi.org/10.1177/0734242X07076946

[24] Behnamfard, A., Salarirad, M.M. and Veglio, F. (2013) Process Development for Recovery of Copper and Precious Metals from Waste Printed Circuit Boards with Emphasize on Palladium and Gold Leaching and Precipitation. Waste 
Management (New York, N.Y.), 33, 2354-2363. http://dx.doi.org/10.1016/j.wasman.2013.07.017

[25] Costa, M.C. (1997) Hydrometallurgy of Gold: New Perspectives and Treatment of Refractory Sulphide Ores. Fizykochemiczne Problemy Mineralurgii, 31, 63-72.

[26] De Michelis, I., et al. (2013) Roasting and Chlorine Leaching of Gold-Bearing Refractory Concentrate: Experimental and Process Analysis. International Journal of Mining Science and Technology, 23, 709-715. http://dx.doi.org/10.1016/j.ijmst.2013.08.015

[27] Baba, A.A., Adekola, F.A., Toye, E.E. and Bale, R.B. (2009) Dissolution Kinetics and Leaching of Rutile Ore in Hydrochloric Acid. Journal of Minerals \& Materials Characterization \& Engineering, 8, 787-801. http://dx.doi.org/10.4236/jmmce.2009.810068

[28] He, Y. and Xu, Z. (2015) Recycling Gold and Copper from Waste Printed Circuit Boards Using Chlorination Process. RSC Advances, 5, 8957-8964. http://dx.doi.org/10.1039/C4RA16231E

[29] Radulescu, R., Filcenco-Olteanu, A., Panturu, E. and Grigoraş, L. (2008) New Hydrometallurgical Process for Gold Recovery. Chemical Bulletin of Politehnica University of Timisoara, 53, 135-139.

[30] Ojeda, M.W., Perino, E. and Ruiz, M.D.C. (2009) Gold Extraction by Chlorination Using a Pyrometallurgical Process. Minerals Engineering, 22, 409-411. http://dx.doi.org/10.1016/j.mineng.2008.09.002

[31] Filcenco Olteanu, A., Dobre, T., Panturu, E., Radu, A.D. and Akcil, A. (2014) Experimental Process Analysis and Mathematical Modeling for Selective Gold Leaching from Slag through Wet Chlorination. Hydrometallurgy, 144-145, 170-185. http://dx.doi.org/10.1016/j.hydromet.2014.02.011

[32] Wang, H.-X., et al. (2013) Study on Gold Concentrate Leaching by Iodine-Iodide. International Journal of Minerals, Metallurgy, and Materials, 20, 323-328. http://dx.doi.org/10.1007/s12613-013-0730-7

[33] Dadgar, A. (1989) Refractory Concentrate Gold Leaching: Cyanide vs. Bromine. JOM, 41, 37-41. http://dx.doi.org/10.1007/BF03220846

[34] (2007) Bromine-Chemical Leaching of Gold. World Placer Journal, 7, 79.

[35] Konyratbekova, S.S., Baikonurova, A., Ussoltseva, G.A., Erust, C. and Akcil, A. (2015) Thermodynamic and Kinetic of Iodine-Iodide Leaching in Gold Hydrometallurgy. Transactions of Nonferrous Metals Society of China, 25, 37743783. http://dx.doi.org/10.1016/S1003-6326(15)63980-2

[36] Li, J., et al. (2012) Thiocyanate Hydrometallurgy for the Recovery of Gold. Part I: Chemical and Thermodynamic Considerations. Hydrometallurgy, 113-114, 1-9.

[37] Li, J., et al. (2012) Thiocyanate Hydrometallurgy for the Recovery of Gold. Hydrometallurgy, 113-114, 10-18. http://dx.doi.org/10.1016/j.hydromet.2011.11.007

[38] Xu, B., et al. (2015) Improved Thiosulfate Leaching of a Refractory Gold Concentrate Calcine with Additives. Hydrometallurgy, 152, 214-222. http://dx.doi.org/10.1016/j.hydromet.2014.12.016

[39] Gos, S. and Rubo, A. (2001) The Relevance of Alternative Lixiviants with Regard to Technical Aspects, Work Safety and Environmental Safety. Cyplus. Degussa AG, Hanau, Germany.

[40] Li, J., et al. (2012) Thiocyanate Hydrometallurgy for the Recovery of Gold. Part V: Process Alternatives for Solution Concentration and Purification. Hydrometallurgy, 113-114, 31-38.

[41] Aylmore, M.G. and Muir, D.M. (2001) Thiosulfate Leaching of Gold—A Review. Minerals Engineering, 14, 135-174. http://dx.doi.org/10.1016/S0892-6875(00)00172-2

[42] SGS Mineral Services (Ed.) (2008) Thiosulphate Leaching-An Alternative to Cyanidation in Gold Processing.

[43] Lampinen, M., Laari, A. and Turunen, I. (2015) Ammoniacal Thiosulfate Leaching of Pressure Oxidized Sulfide Gold Concentrate with Low Reagent Consumption. Hydrometallurgy, 151, 1-9. http://dx.doi.org/10.1016/j.hydromet.2014.10.014

[44] Gabra, G. (1984) A Kinetic Study of the Leaching of Gold from Pyrite Concentrate Using Acidified Thiourea. Precious Metals: Mining, Extraction and Processing, 145-172.

[45] Yannopoulos, J.C. (1991) The Extractive Metallurgy of Gold. Springer, New York. http://dx.doi.org/10.1007/978-1-4684-8425-0

[46] Bruckard, W.J., Sparrow, G.J. and Woodcock, J.T. (1993) Gold and Silver Extraction from Hellyer Lead-Zinc Flotation Middlings Using Pressure Oxidation and Thiourea Leaching. Hydrometallurgy, 33, 17-41. http://dx.doi.org/10.1016/0304-386X(93)90003-V

[47] Whitehead, J.A., Lawrance, G.A. and McCluskey, A. (2004) Green Leaching: Recyclable and Selective Leaching of Gold-Bearing Ore in an Ionic Liquid. Green Chemistry, 6, 313-315. http://dx.doi.org/10.1039/B406148A

[48] Jindra, T., Prokop, Z. and Šnita, D. (2012) Etching and Recovery of Gold from Aluminum Substrate in Thiourea Solution. Chemical Papers, 66, 617-620. http://dx.doi.org/10.2478/s11696-011-0117-z 
[49] Zhang, J., et al. (2014) Dual Lixiviant Leaching Process for Extraction and Recovery of Gold from Ores at Room Temperature. Hydrometallurgy, 144, 114-123. http://dx.doi.org/10.1016/j.hydromet.2014.02.001

[50] Attia, Y.A. and El-Zeky, M. (1989) Bioleaching of Gold Pyrite Tailings with Adapted Bacteria. Hydrometallurgy, 22, 291-300. http://dx.doi.org/10.1016/0304-386X(89)90026-1

[51] US Department of Agriculture (1994) NBIAP News Report.

[52] Fleming, C.A. (1992) Hydrometallurgy of Precious Metals Recovery. Hydrometallurgy, 30, 127-162. http://dx.doi.org/10.1016/0304-386X(92)90081-A

[53] Fomchenko, N.V., Kondrat'eva, T.F. and Muravyov, M.I. (2016) A New Concept of the Biohydrometallurgical Technology for Gold Recovery from Refractory Sulfide Concentrates. Hydrometallurgy, 164, 78-82. http://dx.doi.org/10.1016/j.hydromet.2016.05.011

[54] Savvaidis, I. (1998) Recovery of Gold from Thiourea Solutions Using Microorganisms. Biometals, 11, $145-151$. http://dx.doi.org/10.1023/A:1009234113485

[55] Liu, R., Li, J. and Ge, Z. (2016) Review on Chromobacterium violaceum for Gold Bioleaching from E-Waste. Procedia Environmental Sciences, 31, 947-953. http://dx.doi.org/10.1016/j.proenv.2016.02.119

[56] Sagdieva, M.G., Borminskiy, S. and Rakhmatullaeva, Z. (2007) Biohydrometallurgical Processing of Flotation Tailings from Different Copper Mills. Advanced Materials Research, 20-21, 209-303. http://dx.doi.org/10.4028/www.scientific.net/amr.20-21.299

\section{Submit or recommend next manuscript to SCIRP and we will provide best service for you:}

Accepting pre-submission inquiries through Email, Facebook, LinkedIn, Twitter, etc.

A wide selection of journals (inclusive of 9 subjects, more than 200 journals)

Providing 24-hour high-quality service

User-friendly online submission system

Fair and swift peer-review system

Efficient typesetting and proofreading procedure

Display of the result of downloads and visits, as well as the number of cited articles

Maximum dissemination of your research work

Submit your manuscript at: http://papersubmission.scirp.org/ 